\title{
Рекомендации Американской кардиологической ассоциации и Американской ассоциации инсульта от 2018 года по ранней стратегии ведения пациентов с острым ишемическим инсультом
}

Острый ишемический инсульт - ОАна из важнейших проблем мирового зАравоохранения. Научная и практическая работа в этом направлении ведется непрерывно, поскольку эта патология в структуре серАечно-сосуАистой заболеваемости и смертности преАставляет собой тяжелое бремя Аля социальноэкономической системы как развитых, так и развивающихся стран. В 2018 году Американской карАиологической ассоциацией и Американской ассоциацией инсульта были преАставлены обновленные клинические рекоменАации по ранней стратегии веАения пациентов с острым ишемическим инсультом, поскольку за пять ^ет, истекших с момента публикации послеАних рекоменАаций, накопился большой объем фактического материала. Представлены как совершенно новые, так и переработанные рекоменАации, некоторые прошлые рекоменАации были упразАнены. Материал алресован организаторам зАравоохранения, клиническим специалистам первичного и вторичного звеньев системы медицинской помощи, экспертам смежных областей.

\section{Догоспитальный этап медицинской помощи}

Организаторам заравоохранения, наряау с меАицинскими работниками и специалистами прочих областей, необхоАимо разрабатывать и внеАрять в практику государственные информационно-просветительские программы по инсульту с обязательным акцентом на необходимость немеАленного обращения за экстренной меАицинской помощью в случае появления специфических симптомов. Программы этого типа Аолжны быть системными и непрерывными, охватывать различные группы населения с учетом этнических, возрастных и половых особенностей (к^асс рекоменАаций - I, уровень АОказательности: B-R).

Залог своевременного обращения за экстренной меАицинской помощью - знание и умение распознать первые признаки инсульта. Именно это составляет важнейшую проблему А^я широких слоев населения, в отличие от групп исхоАно повышенного риска, что привоАит к большим отсрочкам в обеспечении пациентов своевременной меАицинской помощью еще на Аогоспитальном уровне. Эпилемиологические Аанные показывают, что усилия, направленные на повышение освеАомленности общественности, Аают разный эффект, что зависит от возраста, пола и национальных особенностей. Учитывая это, просветительские кампании по инсульту Аолжны разрабатываться с учетом аАресHого поАХOAव.

СИстема скорой меАицинской помощи АОлжна ФУнкционировать по принципу приоритетности вызОвов С поАОзрением на инсульт. БригаАы экстренной меАицинской помощи АОлжны выезжать на эти вызовы в приоритетном поряАКе, чтобы максимально сократить время транспортировки пациента Ао меАицинского учрежАения, поскольку пациенты Аолжны начинать получать специфическое лечение в течение не более чем 3 часов (в частности, альтеп^азой) (к^асс рекоменАаций - І, уровень Аоказательности: B-NR).

\section{Оценка и помощь при инсульте в рамках скорой медицинской помощи}

В рамках оказания первой меАицинской помощи, в том числе в Аиспетчерской службе скорой меАицинской помощи (СМП), рекоменАОвано внеАрить Шкалу ОцеНКИ тяжести инсульта.

Совершенно необходимым слеАует считать внеАрение протокола веАения инсульта Аля бригаА СМП. На Аогоспитальном уровне специалисты СМП Аолжны информировать принимающую больницу о том, что к ним транспортируется пациент с подозрением на инсульт, с тем, чтобы до прибытия пациента персонал больницы успел мобилизовать необходимые ресурсы (К^асс рекоменАаций - І, уровень Аоказательности: B-NR).

\section{Система скорой медицинской помощи при инсульте}

РУковоАителям службы скорой меАицинской помощи в сотрУАничестве С местными, регИональными и госуАарственными

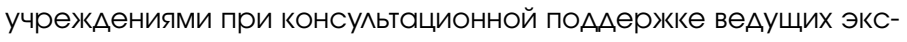
пертов заравоохранения рекоменАуется разработать поАхоАЫ и протоколы, направленные на быстрое выявление и оценку

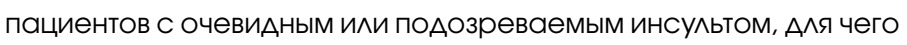
слеАует Использовать валиАированные и станАартизированные инструменты скрининга инсульта, например, тест FAST (face, arm, speech: ^ицо, рука, речь), LAPSS, CPSS (к^асс рекоменАаций-I, уровень Аоказательности: B-NR).

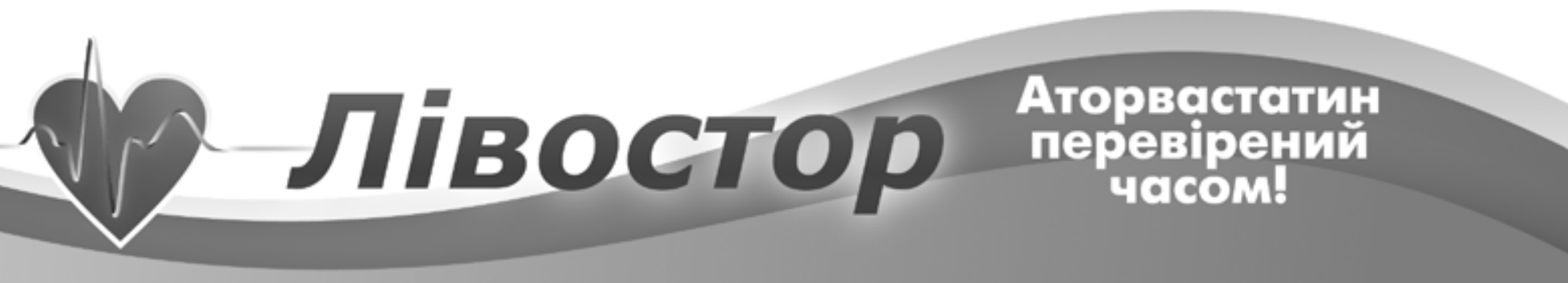


В регионах необходимо созАавать системы меАицинской помощи при инсультах, которая буАет состоять из: 1) меАицинских учрежАений, предоставляющих первичную скорую меАицинскую помощь, ВКАючающую внутривенное ввеАение альтеп^азы; 2) специализированныхцентров, в которыхвозможно провеАение энАОваскулярного ^ечения инсультов, куАа при необходимости пациент может быть быстро транспортирован (класс рекоменАаций - І, уровень Аоказательности: А).

Все пациенты с очевиАным поАОзрением на инсульт АОлжны как можно скорее транспортироваться в ближайшие меАицинские учрежАение, гАе им смогут в оперативном режиме обеспечить внутривенную инфузию альтеплазы.

\section{Экстренная оценка и лечение}

\section{Шкала оценки тяжести инсульта}

РекоменАуется использовать шкалу оценки тяжести инсульта, преАпочтительно NIHSS (шкала тяжести инсульта Национальных институтов зАравоохранения США), приведенную в таблице 1 (кАасс рекоменАациЙ-І, уровень АОказательности: В-NR).

\section{Визуализирующие метоАы исслеАОвания головного мозга}

Всем пациентам непосреАственно после поступления в кАинику с подозрением на острыЙ инсульт необходимо провести АИагностику головного мозга с использованием визуализирующих методов. Обычно А^я этого применяют компьютерную томографию без контрастного усиления, которая позволяет получить нужную А^я принятия решений о стратегии веАения инсульта информацию (КАасс рекоменАаций-І, уровень Аоказательности: B-NR). Применение MPТ в этих целях считается экономически неоправданным, несмотря на более высокую чувствительность этого метода.

СИстема оказания меАИцинской помощи АОлжна строиться так, чтобы визуализирующая Аиагностика головного мозга выполня^ась в течение 20 минут с момента прибытия пациента в больницу хотя бы у половины тех пациентов, которые могут быть канАилатами на внутривенное введение альтеплазы и (или) механическую тромбэктомию (кАасс рекоменАаций - І, уровень Аоказательности: B-NR). Результативность обоих методов ^ечения имеет прямую временную зависимость: чем раньше в рамках терапевтического окна начато ^ечение, тем пропорционально выше положительный эффект.

На Аанный момент отсутствует Аостаточный объем Аанных в пользу определения порога тяжести гиподенсивности тканей и ее распространенности на КТ при остром инсульте, что может повлиять на терапевтический ответ на альтеплазу. Распространенность и тяжесть острого гиподенсивного характера тканей или ранние ишемические изменения не слеАует использовать в качестве критерия Аля отмены этой терапии у пациентов, которые по остальным параметрам поАхоАят А^я такого ^ечения (К^асс
рекоменАаций - III, не рекоменАуется; уровень Аоказательности: B-R).

ГиперАенсивность среАних мозговых артерий по Аанным КТ не слеАует использовать в качестве критерия Аля отмены внутривенного ввеАения альтеплазы у пациентов, которые по остальным параметрам поАхоАят А^я этого ^ечения (КАасс рекоменАаций - III, не рекоменауется; уровень Аоказательности: В-R).

Рутинное применение МРТ Аля исключения церебральных микрокровоизлияний переА внутривенным введением альтеплазы не рекоменАОвано (к^асс рекоменАаций - III, не рекоменАуется; уровень Аоказательности: B-NR).

Проведение мультимоАальной КТ и МРТ, включая визуализацию перфузии, не Аолжно откАаАывать внутривенное ввеАение альтеплазы (кАасс рекоменАаций - III, опасно; уровень Аоказательности: B-NR).

Пациентам, соответствующим критериям провеАения энАОваскулярной терапии, рекоменАуется провоАить неинвазивное внутричерепное сосуАИстое исслеАование при первичном визуализирующем исслеАОвании, но при этом не слеАует заАерживать внутривенное ввеАение альтеплазы (класс рекоменАаций - І, уровень Аоказательности: А).

Пациентам, соответствующим критериям энАОваскулярной терапии, при подозрении на внутричерепную окКАЮзию крупных СоСУАОв КОмПьютерНую ангиографию рекоменАОвано провоАить, не АожиАаясь опреАеления уровня креатинина в сыворотке крови, если в анамнезе отсутствует почечная неАостаточность (кАасс рекоменАаций - lla, уровень Аоказательности: B-NR).

\section{Прочие метоАЫ АИагностики}

Началу внутривенного ввеАения альтеплазы у всех без исключения пациентов Аолжно преАшествовать только опреАеление гАюкозы крови (КАасс рекоменАаций - І, уровень Аоказательности: B-R).

У всех пациентов, поступивших с острым ишемическим ИНСУАьтОМ, РеКОМЕНАУеТся ПрОВОАИть ЭКГ На ИсХОАНОМ УРОВНе, оАнако это не АОлжно влиять на время начала внутривенного ввеАения альтеплазы (кАасс рекоменАаций - І, уровень АОказательности: B-NR).

Аналогичная рекоменАация касается исходного анализа на тропонин.

Ценность рентгенографического исслеАования органов груАной к^етки в сверхострый периоА ишемического инсульта при отсутствии признаков острого поражения легочных и коронарных сосуАОв остается неясной. ОАнако если рентген выполняется, интерпретация его результатов не Аолжна заАерживать внутривенное введение альтеплазы (класс рекомендаций - I, уровень Аоказательности: B-NR).

\section{Антиагрегантная терапия}

Пациентам с острым ишемическим инсультом рекоменАовано введение ацетилсалициловой кислоты в течение 24-48 часов

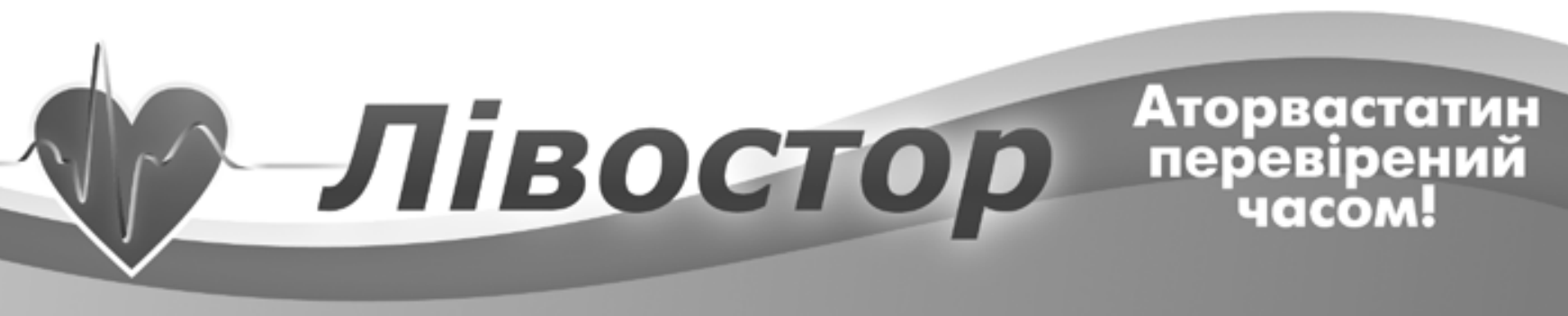


Таблица 1. Шкала оценки тяжести инсульта NIHSS

\begin{tabular}{|c|c|c|}
\hline $\begin{array}{l}\text { Пара- } \\
\text { метр }\end{array}$ & Раздел & Реакция и количество баллов \\
\hline \multirow{4}{*}{$1 \mathrm{~A}$} & \multirow{4}{*}{$\begin{array}{l}\text { Уровень } \\
\text { бодрствования }\end{array}$} & 0 - сознание ясное, живо реагирует \\
\hline & & 1 - оглушение и (или) сомноленция \\
\hline & & 2 - глубокое оглушение или сопор \\
\hline & & 3 - кома, реакции отсутствуют \\
\hline \multirow{3}{*}{$1 B$} & \multirow{3}{*}{$\begin{array}{l}\text { Уровень } \\
\text { бодрствова- } \\
\text { ния: ответы на } \\
\text { вопросы (2) }\end{array}$} & 0 - правильные ответы на оба вопроса \\
\hline & & 1 - правильный ответ только на один вопрос \\
\hline & & 2 - неправильные ответы на оба вопроса \\
\hline \multirow{3}{*}{$1 \mathrm{C}$} & \multirow{3}{*}{$\begin{array}{l}\text { Уровень } \\
\text { бодрствования: } \\
\text { выполнение } \\
\text { команд (2) }\end{array}$} & 0 - правильно выполняет обе команды \\
\hline & & 1 - правильно выполняет одну команду \\
\hline & & 2 - не выполняет ни одну команду \\
\hline \multirow{3}{*}{2} & \multirow{3}{*}{$\begin{array}{l}\text { Движения } \\
\text { глазных яблок }\end{array}$} & 0 - горизонтальные движения в норме \\
\hline & & 1 - частичный парез взора \\
\hline & & 2 - полный паралич взора \\
\hline \multirow{4}{*}{3} & \multirow{4}{*}{ Поля зрения } & 0 - поля зрения без изменений \\
\hline & & 1 - частичная гемианопсия \\
\hline & & 2 - полная гемианопсия \\
\hline & & 3 - двусторонняя гемианопсия \\
\hline \multirow{4}{*}{4} & \multirow{4}{*}{$\begin{array}{l}\text { Функция лице- } \\
\text { вого нерва }\end{array}$} & $0-$ норма \\
\hline & & 1 - легкая слабость мышц лица \\
\hline & & 2 - частичный парез \\
\hline & & 3 - полный односторонний паралич \\
\hline \multirow{5}{*}{5} & \multirow{5}{*}{$\begin{array}{l}\text { Движения в } \\
\text { конечностях } \\
\text { (руки) } \\
\text { а. Левая } \\
\text { б. Правая }\end{array}$} & 0 - рука удерживается \\
\hline & & 1 - рука удерживается в течение 10 секунд \\
\hline & & 2 - рука удерживается менее 10 секунд \\
\hline & & 3 - рука падает без сопротивления силе тяжести \\
\hline & & 4 - активные движения отсутствуют \\
\hline
\end{tabular}

\begin{tabular}{|c|c|c|}
\hline $\begin{array}{l}\text { Пара- } \\
\text { метр }\end{array}$ & Раздел & Реакция и количество баллов \\
\hline \multirow{5}{*}{6} & \multirow{5}{*}{$\begin{array}{l}\text { Движения } \\
\text { в конечностях } \\
\text { (ноги) } \\
\text { а. Левая } \\
\text { б. Правая }\end{array}$} & 0 - нога удерживается \\
\hline & & $\begin{array}{l}1 \text { - нога удерживается в течение } \\
5 \text { секунд }\end{array}$ \\
\hline & & $\begin{array}{l}2 \text { - нога удерживается менее } \\
5 \text { секунд }\end{array}$ \\
\hline & & $\begin{array}{l}3 \text { - падает без сопротивления } \\
\text { силе тяжести }\end{array}$ \\
\hline & & 4 - активные движения отсутствуют \\
\hline \multirow{3}{*}{7} & \multirow{3}{*}{$\begin{array}{l}\text { Атаксия } \\
\text { конечностей }\end{array}$} & 0 - отсутствует \\
\hline & & 1 - в одной конечности \\
\hline & & 2 - в двух конечностях \\
\hline \multirow{3}{*}{8} & \multirow{3}{*}{$\begin{array}{l}\text { Чувствитель- } \\
\text { ность }\end{array}$} & 0 - сохранена \\
\hline & & 1 - легкие нарушения \\
\hline & & $\begin{array}{l}2 \text { - значительное } \\
\text { или полное нарушение } \\
\text { чувствительности }\end{array}$ \\
\hline \multirow{4}{*}{9} & \multirow{4}{*}{ Функция речи } & 0 - норма \\
\hline & & 1 - легкая степень афазии \\
\hline & & 2 - тяжелая афазия \\
\hline & & 3 - мутизм, или тотальная афазия \\
\hline \multirow{3}{*}{10} & \multirow{3}{*}{ Артикуляция } & 0 - норма \\
\hline & & 1 - легкая дизартрия \\
\hline & & 2 - тяжелая дизартрия \\
\hline \multirow{3}{*}{11} & \multirow{3}{*}{$\begin{array}{l}\text { Агнозия } \\
\text { или } \\
\text { игнорирование }\end{array}$} & 0 - нет агнозии \\
\hline & & $\begin{array}{l}1 \text { - легкие признаки } \\
\text { игнорирования } \\
\text { (один вид сенсорной модальности) }\end{array}$ \\
\hline & & $\begin{array}{l}2 \text { - выраженная агнозия } \\
\text { (утрачены две сенсорные } \\
\text { модальности) }\end{array}$ \\
\hline
\end{tabular}

от манифестации. Считается, что у пациентов, которые получают альтеплазу, назначение ацетилсалициловой кислоты обычно откладывается на 24 часа, однако может все-таки рассматриваться при наличии сопутствующей патологии, при которой обычно применяется АСК в отсутствии альтеплазы, что Аает заметную пользу, тогАа как отказ от такого назначения веАет К существенному повышению риска (класс рекоменАаций - I, уровень Аоказательности: А).

Применение ацетилсалициловой кислоты в качестве альтернативного лечения пациентов с острым ишемическим инсультом, если они соответствуют критериям назначения внутривенной альтеп^азы или провеАения механической тромбэктомии (кАасс рекоменАаций - III, не рекоменАуется; уровень Аоказательности: B-R).

Применение Аругих блокаторов гликопротеиновых Illb/lla рецепторов, в том числе абциксимаба, при остром ишемическом инсульте является потенциально опасным и не Аолжно использоваться (к^асс рекоменАаций - III: опасно; уровень Аоказательности: В-R).

У пациентов с малым инсультом Аля ранней вторичной профилактики повторного инсульта сроком АО 90 АНей от появления симптомов рекоменАуется назначать Авойную антиагрегантную терапию (ацетилсалици^овую кислоту и к^опиАогрел) в течение 21 Аня, начиная со вторых суток после инсульта (класс рекоменАаций - Iа; уровень Аоказательности: B-R).

Тикагрелор (в Аополнение к ацетилсалициловой кислоте) не рекоменауется применять при терапии пациентов с малым инсультом в остром периоАе (к^асс рекоменАаций - III: неэффективно; уровень АОказательности: В-R).

\section{d תівостор Aropececrarth}




\section{Антикоагулянты}

При лечении пациентов с острым ишемическим инсультом не рекоменауется провоАить экстренную антикоагуляционную терапию с целью преАотвращения раннего повторного инсульта, Аля торможения нарастания неврологической симптоматики или улучшения общих результатов лечения ОИИ (класс рекоменАаций - III: неэффективно; уровень Аоказательности: А).

Польза от экстренной антикоагулянтной терапии у пациентов с тяжелым стенозом внутренней сонной артерии, расположенной ипсилатерально очагу ишемического инсульта, окончательно не установлена (к^асс рекоменАаций - llb, уровень Аоказательности: B-NR). Безопасность и польза кратковременной антикоагулянтной терапии при неокк^юзионном экстракраниальном внутрипросветном тромбозе на фоне ОИИ Ао конца не определены (Класс рекоменАаций-llb, уровень АОказательности: C-LD).

Увеличение Объема крови/гемоАилюция, вазоАилататоры и гемодинамическая аугментация

Увеличение объема циркулирующей крови за счет гемоди^юции при лечении пациентов с острым ишемическим инсультом не рекоменАОвано (кАасс рекоменАаций - III: неэффективно; уровень Аоказательности: А).

Пациентам с ОИИ не слеАУет ввоАить ВысОКОАОзНЫЙ альбумин (кАасс рекоменАаций - III: неэффективно; уровень Аоказательности: A).

Введение вазодилататоров, в частности пентоксифимлина, не рекоменАОвано при лечении пациентов с ОИИ (к^асс рекоменАаций - III: неэффективно; уровень Аоказательности: А).

МетоА инструментальной аугментации мозгового кровотока при лечении пациентов с острым ишемическим инсультом в настоящее время недостаточно изучен, поэтому может применяться ИскАючительно в Рамках кАинических ИсслеАОваний (к^асс рекоменАаций - Ilb; уровень АОказательности: B-R).

\section{Нейропротекторы}

Современные методы фармакологической и нефармакологической терапии с предполагаемыми нейропротекторными свойствами не показали эффективности в улучшении исхоАОв лечения после ишемического инсульта, поэтому применение ^юбых иных нейропротекторов не рекоменАовано (к^асс рекоменАаций - III: неэффективно; уровень Аоказательности: А).

\section{Профилактика тромбоза глубоких вен}

В Аополнение к станАартному веАению (аспирин и гиАратация) у иммобилизованных пациентов, не имеющих противопоказаний, рекоменауется проводить переменную пневмокомпрессию (ППК) Аля Снижения риска тромбоза глубоких вен (ТГВ).

Эффективность ввеАения поАКожного гепарина (нефракционированного гепарина (НФГ) или низкомолекулярного гепарина (НМГ)) в профилактических АОзах у иммобилизованных пациентов с ОИИ на Аанный момент изучена неАостаточно (к^асс рекоменАаций - Ilb; уровень Аоказательности: A).
При профилактическом провеАении антикоагулянтной терапии преимущество НМГ в профилактических АОзах переА НФГ в профилактических АОзах не установлено (кАасс рекоменАаций - llb; уровень Аоказательности: B-R).

Использование эластического компрессионного белья при ишемическом инсульте строго противопоказано (к^асс рекоменАаций - III: опасно; уровень Аоказательности: B-R).

\section{Госпитальная практика вторичной профилактики инсульта}

\section{МеАицинская визуализация головного мозга}

Рутинное применение МРТ у всех пациентов с острым ишемическим инсультом экономически не целесообразно и не рекоменАуется А^я первоначальной Аиагностики или при п^анировании стратегии лечения (КАасс рекоменАаций - III: неэффективно; уровень Аоказательности: B-NR); оАнако, у некоторых пациентов с ишемическим инсультом МРТ все же рассматривается с целью получить АОполнительную информацию на первичном этапе Аиагностирования или при планировании Аальнейшего лечения, хотя его влияние на исхоА ^ечения остается неясным (к^асс рекоменАаций-llb; Уровень АОказательности: С-ЕО).

\section{МеАИцинсКая вИЗУализация СОСУАИстоЙ СИстеМЫ}

У пациентов без инвалиАизации (оценка по моАифицированной шкале Рэнкина 0-2) с острым ишемическим инсультом в бассейне сонной артерии, которым показаны каротидная энАартерэктомия или стентирование, рекоменАОвано выполнение неинвазивной меАицинсКОЙ визУализации шейных СОСУАОВ в течение первых суток с момента поступления в кАинику (к^асс рекоменАаций - І; уровень Аоказательности: B-NR).

При остром ишемическом инсульте не рекоменАуется п^анировать вторичную профилактику по результатам станАартной компьютерно-томографической ангиографии и магнитно-резонансной ангиографии, проводимых с целью выявления стеноза или окк^Юзии внутричерепных артерий (класс рекоменАаций - III: неэффективно; уровень АОказательности: А), оАнако, у некоторых пациентов с ишемическим инсУльтом этот поАХОА вСе Же иноГАа Используется, хотя его влияние на исхоА Аечения остается неясным (КАасс рекоменАаций - llb; уровень АОказательности: C-ЕО).

\section{Оценка Функции серАца}

РекоменАуется провоАить КарАИомОНиторинг ААя Выявления фибрил^яции преАсерАий и Аругих потенциально серьезных карАиоаритмий, которые могут потребовать экстренного карАиохирургического вмешательства. КарАиомониторинг проводят как минимум в течение первых суток (к^асс рекоменАаций - I; уровень Аоказательности: B-NR).

Клиническая польза от проАленного КарАиомониторинга А^я выявления фибримляции преАсерАий после ОИИ остается неясной (к^асс рекоменАаций - Ilb; уровень АОказательности: B-R).

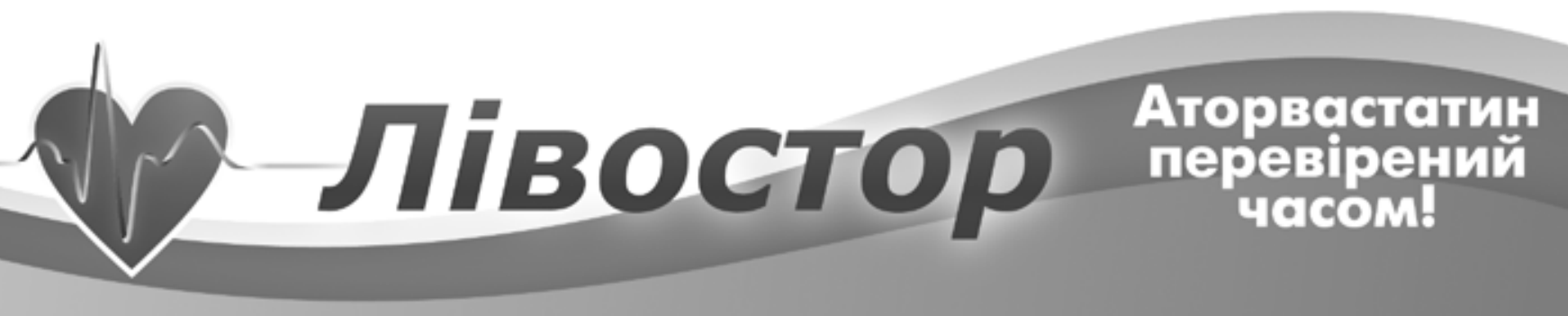


Рутинное применение эхокардиографии у всех пациентов с ОИИ при планировании вторичного профилактического ^ечения экономически нецелесообразно и не рекоменАовано (кАасс рекоменАаций - III: неэффективно; уровень Аоказательности: B-NR).

\section{Уровень холестерина}

Рутинное определение уровня холестерина у всех пациентов с ишемическим инсультом преАположительно атеросклеротического характера, которые на Аанный момент не получают высокоактивный режим терапии статинами, не рекоменАуется (к^асс рекоменАаций - III: неэффективно; уровень Аоказательности: В-R).

Определение уровня холестерина у всех пациентов с ишемическим инсультом преАположительно атеросклеротического характера, которые на Аанный момент получают сбалансированный режим терапии статинами, может помогать выяв^ять пациентов, которым показано амбулаторное лечение ингибиторами пропротеиновой конвертазы субтилизин-кексинового типа 9 Аля Снижения риска серАечно-сосуАистой смерти, ИМ или инсульта в Аальнейшей перспективе (к^асс рекоменАаций - Ilb; уровень Аоказательности: В-R).

Прочие метоАы вторичной профилактики

У всехпациентов, поступивших с острым ишемическим инсуль-

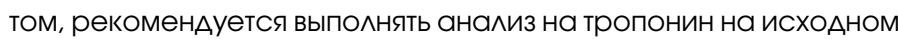
уровне, оАнако это не АОлжно влиять На время начала внутривенного ввеАения альтеп^азы или механическую тромбэктомию (к^асс рекоменАаций - І, уровень Аоказательности: B-NR).

Пациентам с недавно перенесенным ишемическим инсультом не показан п^ановый рутинный контроль гипергомоцистеинемии (к^асс рекоменАаций - III: неэффективно; уровень Аоказательности: С-ЕО).

\section{Антитромботическая терапия}

Пациентам с некардиоэмболическим острым ишемическим инсультом РеКОменАУется ОТАавать преАПОчтенИе антиагрегантам, а не пероральной антикоагулянтной терапии с целью снижения риска повторНого инсУльТа И прочих СерАечно-СОСУАИстых ОСАОЖнений (класс рекоменАаций - І, уровень АОказательности: А).

У пациентов с некардиоэмболическим острым ишемическим инсультом, получающих ацетилсалициловую кислоту, повышение Аозы АСК или замена ее на Аругой антиагрегантный препарат в целях получения Аополнительной пользы в рамках вторичной профилактики инсульта, АО конца не изучено (кАасс рекоменАаций - Ilb; уровень Аоказательности: B-R).

У пациентов с некарАиоэмболическим острым ишемическим инсультом, получающих антиагрегантную терапию, перехоА на варфарин в целях вторичной профилактики инсульта неэффективен (класс рекоменАаций - III: неэффективно; уровень Аоказательности: B-R).
А^я ранней вторичной профилактики у пациентов с некарАиоэмболическим острым ишемическим инсультом поАбирать антиагрегантный препарат слеАует в инАивиАуальном поряАКе с учетом балансов факторов риска, стоимости, переносимости, установленной относительной эффективности препаратов и Ар (к^асс рекоменАаций - І; уровень Аоказательности: С-ЕО).

\section{Терапия статинами}

У пациентов, которые на момент развития ишемического инсульта уже принимают статины, продолжение статинотерапии в остром ПериоАе слеАУет считать целесообразным (кАасс рекоменАаций - Ila; уровень АОказательности: B-R).

Высокоинтенсивная терапия статинами показана к назначению или проАолжению в качестве терапии первой ^инии у пациентов обоего пола в возрасте млаАше 75 ^ет с клинически манифестировавшей атеросклеротической серАечно-

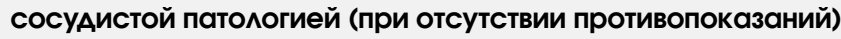
(кАасс рекоменАаций - І; Уровень АОКазательности: А).

У Аиц С кАинически маниФестировавшей атеросклеротической серАечно-сосУАИстой патологией при наличии противопоказаний к высокоинтенсивной терапии статинами, которая при прочих обстоятельствах обязательно назнача^ась бы, ияи особенностей, указывающих на преАрасположенность к побочным реакциям статинотерапии, в качестве Второй ^инии слеАУет использовать Умеренно интенсивную терапию статинами (при условии нормальной переносимости) (КАасс реКоменАаций - І; Уровень АОКазательности: А).

У ^иц старше 75 лет с кАинически манифестировавшей атероскАеротической СерАечно-СосУАИстой ПатологИей целесообразно выполнить оценку потенциала пользы от снижения риска АССП, а также побочных эффектов и реакций лекарственного взаимоАействия, и учесть преАпочтения пациента при назначении умеренно и высокоинтенсивной терапии статинами. При нормальной переносимости статинотерапию необхоАимо проАолжать (КАасс рекоменАаций - Ilb; уровень АОказательности: C-EO).

Пациентов с ишемическим инсультом и Аругими сопутствующими АССП во всех прочих ситуациях необхоАимо вести в Соответствии с рекоменАवциями по холестерину от АСС/АНА 2013 гоАа, которые вкАючают изменения образа Жизни, РеКОМенАवциИ По Рациону и МеАИкаментозномУ лечению (кАасс реКомеНАаций - І; уровень АОКазательности: А).

У пациентов с ОИИ, которым показана статинотерапия, назначение статинов слеАует считать целесообразным уже на госпитальном уровне (кАасс рекоменАаций - ІІа; уровень Аоказательности: C-LD).

ААаптований перек^аА виАавництва «МеАікс груп»

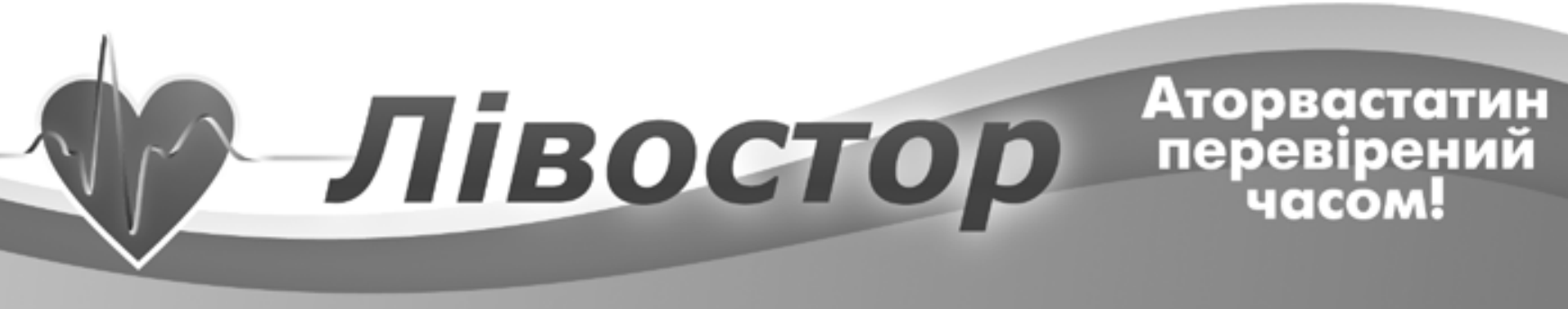

